Article

\title{
Preparation and Characterization of Chitosan-Alginate Polyelectrolyte Complexes Loaded with Antibacterial Thyme Oil Nanoemulsions
}

\author{
Hamid Hamedi *, Sara Moradi, Alan E. Tonelli * and Samuel M. Hudson \\ Textile Engineering Chemistry and Science, Fiber \& Polymer Science Program, College of Textiles, North Carolina \\ State University, Raleigh, NC 27606, USA; s-moradi@phd.araku.ac.ir (S.M.); shudson@ncsu.edu (S.M.H.) \\ * Correspondence: hhamedi@ncsu.edu (H.H.); atonelli@ncsu.edu (A.E.T.)
}

Received: 10 August 2019; Accepted: 16 September 2019; Published: 19 September 2019

\begin{abstract}
Biomedical industries are attempting to utilize natural materials, as they are bio-compatible, non-toxic, and show bioactive properties, like antimicrobial activity. In this study, natural polyelectrolyte complexed chitosan/alginate films (PECs) were prepared via a casting/solvent evaporation technique, and their characteristics and drug release properties were investigated. PEC films made with two different overall polymer contents, 0.4 and $1 \mathrm{w} / \mathrm{v} \%$, were loaded with thyme oil nanoemulsion as drug carrier. The structure of the films was studied by FTIR and optical and scanning electron microscopy. Prepared PEC films had good mechanical and water vapor permeability properties. Release of the thyme oil from the $\mathrm{pH}$-sensitive PEC films (TM-PEC) was detected and followed by UV spectroscopy. The results indicated that the drug release rate of TM-PEC films was the fastest when the chitosan content was $1 \% \mathrm{w} / \mathrm{v}$, and various mathematical models were analyzed for investigating the drug release mechanism. Antibacterial tests were performed by counting the number of surviving gram-negative and gram-positive bacteria. The in vitro test indicated the limitation Escherichia coli (E. coli) and Staphylococcus aureus (S.aureus) growth in the presence of TM-PEC films. The MTT test showed more cell viability of the TM-PEC film in comparison with that of the PEC film without TM. Based on the measured physical and antibacterial properties, the chitosan-alginate PEC films loaded with antibacterial essential oils can be considered for biomedical applications, such as wound dressings or controlled release systems.
\end{abstract}

Keywords: polyelectrolyte complex; chitosan; alginate; thyme oil nanoemulsion; biomedical applications

\section{Introduction}

The neutralization and bridging produced by electrostatic forces is the major mechanism for the formation of polyanion-polycation polyelectrolyte complexes (PEC). There are several factors that affect PEC formation, such as degree of ionization or charge density, position of ionic groups on the polyionic chains, concentration, molecular weight, composition, and mixing order. $\mathrm{PH}$ and temperature of the medium are also important [1]. PECs have unique physicochemical properties, which are different from those of their individual components, with a wide range of applications as membranes [2,3], scaffolds [4,5], fibers [6,7], and microcapsules [1,8]. Alginate and chitosan are interesting biopolymers because they are cheap and well tolerated by the immune system $[9,10]$. Their use in PECs is widely reported [11-13]. Moreover, alginate-chitosan PECs have an impressive effect of limiting the release of encapsulated materials compared to either charged polymer alone [11].

Alginate is derived from seaweed and is an anionic block copolymer of $\alpha-(1-4)$-L-guluronic $(G)$ and $\beta$-(1-4)-D-mannuronic acid (M), which is usually present as the sodium salt. Alginate, an acidic 
linear polysaccharide, is chemically stable at $\mathrm{pH}$ values between 5 and 10. It can be converted into a hydrophilic gel which provides a moist wound environment and promotes healing process and epidermal regeneration [2]. The generic term "chitosan", which is the deacetylated form of chitin, describes a range of presumably pure poly-(beta-1-4) N-acetyl-D-glucosamine materials. Chitosan is synthesized by various number of living organisms, such as insect cuticles and crustacean skeletons, e.g., crab, shrimp and lobster, and fungi [12]. Chitosan with excellent cell-adhesive properties and bacteriostatic effects can accelerate wound healing process [13].

Chitosan and alginate polysaccharides are both biocompatible and nontoxic materials (Figure 1), so their PEC films are non-cytotoxic towards human fibroblasts. Lee et al. [14] showed that human fibroblast cells on the PEC of sodium alginate and Chitosan retained more than $91 \%$ viability over a 4-day period of exposure. Chitosan-alginate membranes have been studied for low molecular weight drug delivery in a wound dressing. A 1:1 ratio of chitosan and alginate gives the greatest viscosity and a high porosity structure, and because of the complete pairing effect of ionic materials, less functional groups are accessible for reacting with drugs [15].

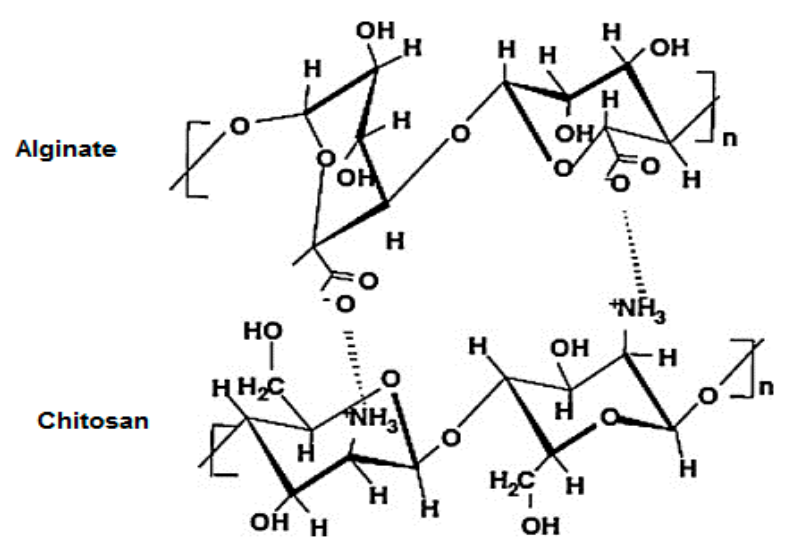

Figure 1. Structure of chitosan-alginate PEC.

Because of the high antimicrobial, antioxidant, and antifungal activities of essential oils, their use in different fields, like the food, cosmetic, and pharmaceutical industries, has been increasing recently [16]. Thyme oil extracted from Thymus vulgaris has shown inhibitory activities against different bacteria and yeasts $[17,18]$. The major constituents of thyme essential oil, which is rich in phenolic phytochemicals, have been reported to be thymol, carvacrol, and $\gamma$-terpinene $[19,20]$. Antimicrobial activity of twenty plant oils and extracts against Candida albicans (C. albicans), Staphylococcus aureus (S. aureus) and Escherichia coli (E. coli) was investigated by Hammer et al. [21]. The lowest minimum inhibitory concentration was obtained $0.03 \%(\mathrm{v} / \mathrm{v})$ for thymol against C. albicans and E. coli. In a case study done by Nardelli et al. [22], different topical pharmaceutical products marketed in Belgium containing fragrances were tested on 18,960 patients to investigate their allergic contact effects. In this study, products with thyme oil or thymol showed the lowest allergic effects, which is also confirmed by Schilcher [23]. Encapsulation of essential oils in nanoemulsions has proved a new strategy for improving their efficacy, stability, and utilization [24]. Nanoemulsions are categorized as nanosized delivery systems for lipophilic compounds, such as flavors [25], vitamins [26], and antimicrobials [27]. Owing to their smaller particle sizes, nanoemulsions are much more stable against flocculation, coalescence, and creaming [28], which makes them an excellent candidate for food industries and as delivery agents for pharmaceuticals and drugs.

To the best of our knowledge, loading of essential oils in alginate-chitosan PEC films has not been studied previously. There are some studies about loading essential oils in chitosan-alginate beads or capsules which have different structures from that of film. In this study, thyme oil nanoemulsion (TM-nanoemulsion) has been successfully loaded in polyelectrolyte complexes of chitosan and alginate as a drug carrier. Prepared films were characterized using FTIR, SEM, swelling ratio, $\mathrm{pH}$ sensitivity, gel 
fraction, MTT assay and antibacterial activity against E.coli and S.aureus. In addition, release studies of thyme oil from the films and release mechanisms were investigated in detail to find the best controlled released system. The results of this research have important applications for the design and use of PEC films loaded with TM nanoemulsions for pharmaceutical applications, such as wound dressings and drug delivery systems.

\section{Material and Methods}

\subsection{Material}

Medium molecular weight chitosan (Natural Biopolymer Inc., $\mathrm{M}_{\mathrm{W}}=7.4 \times 10^{5} \mathrm{~g} / \mathrm{mol}, \mathrm{DD}=95.3$ ) alginic acid sodium salt (Sigma, medium viscosity, A-2033), thyme oil (Spectrum Chemical MFG Corp T1047), tween 80 (Merck KGa, density $=1.06-1.090$ at $20^{\circ} \mathrm{C} / 4^{\circ} \mathrm{C}$ ), buffer solutions at $\mathrm{pH}=4,7$, and 10 (Dow Chemical company), phosphate buffered saline (Sigma Aldrich Chemical Company), Tryptic Soy Agar (TSA, BD, USA) and Bacto ${ }^{\mathrm{TM}}$ Tryptic Soy Broth (TSB, BD, USA) were purchased and used without further purification.

\subsection{Nanoemulsion Preparation}

At ambient temperature, $2 \% \mathrm{v} / \mathrm{v}$ Tween 80 was solved in distilled water and shook with a magnetic type stirrer at $500 \mathrm{rpm}$ for 5 minutes. Then thyme oil was added slowly to reach desired concentrations $(1,2$, and $3 \% \mathrm{v} / \mathrm{v})$. The resulting crude emulsion was sonicated using a Misonix Sonicator XL 2020 homogenizer. The sonication time was 30 minutes for all cases. Sonication applies ultrasonic frequencies to agitate particles in a sample to speed up dissolution by breaking intermolecular interactions and preventing aggregation of particles. Ultrasonication generates intensive and disruptive forces in order to minimize the size of nanoemulsion droplets [29]. Al-Kaysi et al. [30] demonstrated that sonication provides an approach to exert control over particle size, morphology, and colloidal stability. Sonicators are commonly used for dispersing, deagglomeration, reducing particle sizes, precipitation, and surface functionalization [31]. The resultant nanoemulsions were stored in the laboratory condition $\left(25^{\circ} \mathrm{C}\right)$.

\subsection{Polyelectrolyte Complex Preparation}

Chitosan powder was dissolved in $2 \% \mathrm{v} / \mathrm{v}$ aqueous acetic acid and acetone to yield concentrations of 0.4 and $1 \% \mathrm{w} / \mathrm{v}[2,32,33]$. Sodium alginate was dissolved in distilled water to form homogeneous solutions of 0.4 and $1 \% \mathrm{w} / \mathrm{v}$. To a $25 \mathrm{~mL}$ of equivalent concentration of sodium alginate solution, $25 \mathrm{~mL}$ of each chitosan solution was added drop wise ( $1 \mathrm{~mL} / \mathrm{min}$ by NE-1010 Syringe Pump) and stirred with a high speed mechanical mixer for $20 \mathrm{~min}$. TM-nanoemulsion of $1 \mathrm{v} / \mathrm{v} \%$ was selected as the best prepared solution. Therefore, $50 \mathrm{~mL}$ of the TM-nanoemulsion was added to the $50 \mathrm{ml}$ chitosan-alginate solution to reach a final concentration of $0.5 \% \mathrm{v} / \mathrm{v}$ and mixed for $10 \mathrm{~min}$. The resultant suspension was cast onto a polyethylene petri dish and dried overnight at ambient temperature $\left(25^{\circ} \mathrm{C}\right)$ to yield a homogeneous PEC film. The final prepared films were named TM-PEC $\% 1$ and TM-PEC $\% 0.4$ based on their polymer content ( 1 and $0.4 \% \mathrm{w} / \mathrm{v}$ respectively).

\section{Characterization}

\subsection{Entrapment Efficiency (EE) and Drug Loading (DL)}

The amount of thyme essential oil encapsulated in the nanoemulsion solution was calculated spectrophotometrically (Lambda 25, PerkinElmer) at $274 \mathrm{~nm}$. In $5 \mathrm{~mL}$ of $95 \mathrm{~mL} / 100 \mathrm{~mL}$ acetonitrile/water solution, $500 \mu \mathrm{L}$ nanoemulsions were solved and blended for $48 \mathrm{~h}$ to make sure that all the entrapped active compounds were released into the solution. The EEs and DLs of the TM-nanoemulsions were calculated by the Equations (1) and (2) [34,35].

$$
\mathrm{EE}=\frac{\text { Amount of active compound entrapped }}{\text { Initial amount of thyme oil }} \times 100
$$




$$
\mathrm{DL}=\frac{\text { Amount of active compound entrapped }}{\text { Initial amount of nanoemulsion solution }} \times 100
$$

\subsection{Particle Size and Charge Measurements}

The dynamic light scattering experiments (DLS) were conducted using a DLS, Zetasizer Nano (Malvern, UK) instrument. The nanoemulsions were diluted with distilled water to a suitable concentration (1:10) at room temperature before analysis to prevent influence of multiple scattering.

\subsection{Morphology Studies}

Surface morphology of the PEC films was examined with a Nikon Eclipse 50i-POL optical microscope equipped with a Nikon DSFi1 camera. Internal surface and cross-section structure of the PEC films were also examined by a scanning electron microscope (Seron Technologies, AIS2100). To do this, films were frozen in liquid nitrogen for 5 minutes and then fractured for drug loading observation.

\subsection{Fourier Transform Infrared Spectroscopy (FTIR)}

FTIR spectra were used to confirm the formation of PEC and TM-PEC films [2,36]. Analysis was carried out by using a Nicolet iS10 (ThermoFisher, United State) spectrophotometer in the range from $600-4000 \mathrm{~cm}^{-1}$ at resolution of $4 \mathrm{~cm}^{-1}$. All films were analyzed in the absorbance mode.

\subsection{PEC Swelling Ratio}

The PEC films were soaked in distilled water at ambient temperature until reached a constant weight. At specified time intervals, the hydrogel was removed, and the excess water on the surface was dried by filter paper and weighed. The swelling ratio was calculated according to Equation (3):

$$
\% \mathrm{SR}=\left[\left(\mathrm{W}_{\text {wet }}-\mathrm{W}_{\mathrm{dry}}\right) / \mathrm{W}_{\mathrm{dry}}\right] \times 100
$$

where, $\mathrm{W}_{\text {wet }}$ and $\mathrm{W}_{\mathrm{dry}}$ represent the weight of wet and dried films, respectively.

\subsection{Water Vapor Transmission Rate}

The water vapor transmission tests were performed according to the ASTM standard. A round piece of PEC film was placed on the top of a cup ( $36 \mathrm{~mm}$ diameter) containing $10 \mathrm{~mL}$ of distilled water and put in an incubator of $35 \%$ relative humidity at $37^{\circ} \mathrm{C}$. The films were fastened using Teflon tape across the edges to prevent any water vapor loss. The cups were weighed at specific time intervals, and WVTR was determined by Equation (4):

$$
\operatorname{WVTR}\left(\mathrm{g} / \mathrm{m}^{2} / \text { day }\right)=[\mathrm{s} \times 24] / \mathrm{B}
$$

where $s$ is the slope of weight loss versus time plot, and B is the area of cup mouth in $\mathrm{m}^{2}$.

\section{7. $p H$ Sensitivity}

The $\mathrm{pH}$-sensitivity behaviors of PEC films were studied in different phosphate buffer solutions with various $\mathrm{pH}$ values $(\mathrm{pH}=4,7$, and 10) [37]. The dried hydrogels were soaked in buffer solution until reached the equilibrium state of swelling. The hydrogel was removed and the excess buffer solution on the surfaces was dried by filter paper and weighed. Values of the swelling ratio were then calculated according to the Equation (3).

\subsection{Mechanical Test}

Tensile strength of the PEC films was determined using a Z010 Zwick/Roell Universal apparatus. PEC films (Slab shaped) with $10 \mathrm{~mm}$ width and $20 \mathrm{~mm}$ length were cut and thickness determined using a caliper (thickness was in the range of 1-2 $\mathrm{mm}$ ). The tension and elongation at break were 
measured at a speed of $10 \mathrm{~mm} / \mathrm{min}$ at room temperature. The elastic modulus was then calculated from the observed stress-strain behavior. Each test was repeated at least 3 times, and the averages were reported as the final values.

\subsection{Cytotoxicity Test}

The toxicity of the PEC extracts was quantitatively evaluated by MTT assay on L929 cells. The method was described previously [38]. Briefly, alginate-chitosan solutions containing TM-nanoemulsion were prepared, poured into a 96-well plate and dried overnight. When TM-PEC films were prepared and sterilized under UV exposure for 30 minutes, then $200 \mu \mathrm{L}$ of sterile normal saline was added to each well and incubated at $37^{\circ} \mathrm{C}$ for $24 \mathrm{~h}$. About $50 \mu \mathrm{L}$ of each extract and $50 \mu \mathrm{L}$ of nanoemulsion was added separately to each 24 -well plate containing $450 \mu \mathrm{L}$ of cell suspension $\left(10^{4}\right.$ cells $\left./ \mathrm{mL}\right)$ in RPMI-1640 media supplemented with $10 \%$ fetal bovine serum (FBS) in triplicate. Negative control wells were considered as cell suspension without extracts. Plates were incubated for 24 and $48 \mathrm{~h}$ in a $\mathrm{CO}_{2}$ incubator at $37^{\circ} \mathrm{C}$ with $5 \% \mathrm{CO}_{2}$ and $85 \%$ humidity. After each period of incubation, $100 \mu \mathrm{L}$ MTT $(5 \mathrm{mg} / \mathrm{mL})$ solutions were added to each of the wells and incubated for an extra $4 \mathrm{~h}$. Cells were washed with phosphate buffer saline (PBS). To each well, $0.5 \mathrm{~mL}$ DMSO was then added, and final optical densities were measured at $570 \mathrm{~nm}$.

\subsection{In Vitro Test}

The antibacterial activities of the PEC films against E. coli, Gram-negative bacteria, ATCC\# 25922) and S.aureus, Gram-positive bacteria, ATCC\# 33591) were evaluated by using the viable cell counting method, which was described previously [38]. Each bacteria was cultivated in a Tryptic Soy broth medium separately (17 g/L Casein, $3 \mathrm{~g} / \mathrm{L}$ Soybean Peptone, $2.5 \mathrm{~g} / \mathrm{L}$ Dextrose, $5 \mathrm{~g} / \mathrm{L}$ Sodium Chloride, and $2.5 \mathrm{~g} / \mathrm{L}$ Dipotassium Phosphate) to obtain an optical density of 0.2 (about $2 \times 10^{7} \mathrm{CFU} / \mathrm{mL}$ ). PEC films (with or without thyme oil nanoemulsion) with an average weight of $30 \mathrm{mg}$ and $100 \mu \mathrm{L}$ of TM-nanoemulsion were soaked (or mixed) separately with $1 \mathrm{ml}$ bacteria/TSB solution and incubated for $24 \mathrm{~h}$ in a shaker at $37^{\circ} \mathrm{C}$. For preparing decimal dilutions, $100 \mu \mathrm{L}$ of the bacteria/TSB solution was mixed with $900 \mu \mathrm{L}$ of broth medium. On an agar plate, $10 \mu \mathrm{L}$ of the diluted bacteria/TSB solution was slowly spread (15 g/L Pancreatic Digest of Casein, $5 \mathrm{~g} / \mathrm{L}$ Papaic Digest of Soybean, $5 \mathrm{~g} / \mathrm{L}$ Sodium Chloride, and $15 \mathrm{~g} / \mathrm{L}$ Agar). Plates were incubated for $24 \mathrm{~h}$ at $37^{\circ} \mathrm{C}$ and then the number of bacteria was counted. A blank PEC film without TM-nanoemulsion and nanoemulsion without thyme oil was used as the control.

\subsection{Drug Release}

Each of the PEC films loaded with TM-nanoemulsion (TM-PEC) was immersed in $10 \mathrm{~mL}$ of phosphate buffer solution at $37^{\circ} \mathrm{C}$ in a Thermo-Fisher shaker ( $\left.\mathrm{pH} 7.4\right)$. At regular time, $3 \mathrm{~mL}$ of the solution were removed, and the same volume of buffer solution was added to keep the volume at a constant level. The amount of the released thyme oil was calculated at a wavelength of $274 \mathrm{~nm}$ using a Lambda 25, PerkinElmer spectrophotometer. A blank PEC film without TM-nanoemulsion was used as the control.

\subsection{Drug Release Kinetics}

To realize the release mechanism of thyme oil from the PEC films into Buffer solution, the release rate was modeled by the semi-empirical Korsmeyer-Peppas equation (Equation (5)) [39].

$$
\mathrm{M}_{\mathrm{t}} / \mathrm{M}_{0}=\mathrm{k} \cdot \mathrm{t}^{\mathrm{n}}
$$

where $M_{t} / M_{0}$ is the fraction of drug released at time $t$ and $k$ and $n$ are constant values describing the macromolecular network system and transport mechanism. The parameter $\mathrm{n}$ is dependent on the geometry of the structure and the physical transport mechanism of solute [40]. As the k value increases, 
the drug releases faster [41]. Detailed interpretations of the release parameters $\mathrm{n}$ and $\mathrm{k}$ are given in Table S1 [42].

Different kinetics models, explained as follows (Equations (6)-(9)) [43,44], were also employed to understand the kinetics of drug release from the film network:

$$
\begin{gathered}
\text { Zero-order: } C_{t}=C_{0}+k_{0} \cdot t \\
\text { First-order: } \log C_{t}=\log C_{0}-k_{1} \cdot t / 2 \cdot 303 \\
\text { Higuchi: } C_{t}=k_{H} \cdot t^{1 / 2} \\
\text { Hixson-Crowell: } C_{0 H C}{ }^{1 / 3}-C_{t H C}{ }^{1 / 3}=k_{H C} \cdot t
\end{gathered}
$$

$C_{t}$ is the concentration of drug at time $t, C_{0}$ is the concentration of drug at time $=0$ (usually, $C_{0}=0$ ), $k_{0}$ is the zero-order constant, $\mathrm{k}_{1}$ is the first-order constant, $\mathrm{k}_{\mathrm{H}}$ is the Higuchi constant, $\mathrm{C}_{0 \mathrm{HC}}$ is the initial concentration of the drug in film, $\mathrm{C}_{\mathrm{tHC}}$ is the remaining concentration of drug in dosage form at time $\mathrm{t}$, and $\mathrm{k}_{\mathrm{HC}}$ is Hixson-Crowell constant.

\subsection{Drug Release Method Validation}

The method validation was performed by ICH guidelines [45]. The limits of quantification (LOQ) and detection (LOD) were calculated based on the relationship between the standard deviation (SD) of the calibration curve and its slope (S) using the following equations [46]: $\mathrm{LOD}=(3 \mathrm{SD} / \mathrm{S})$ and $\mathrm{LOQ}=$ $(10 S D / S)$. Linearity was calculated by the determination of regression coefficient $\left(\mathrm{r}^{2}\right)$.

\subsection{Statistical Analysis}

Microsoft Excel software was applied to calculate $p$ values by $\mathrm{t}$ test and analysis of variance (ANOVA). Values of $p<0.05$ were considered statistically significant.

\section{Results and Discussion}

\subsection{Entrapment Efficiency and Drug Loading}

Entrapment efficiency is the percentage of drug which is entrapped into the nanoparticles. The calculated EE for TM-nanoemulsion was $71 \mathrm{~g} / 100 \mathrm{~g}$ meaning that the $70 \%$ of the thyme oil is entrapped into the nanoemulsions, which indicates good entrapment. Loss of $30 \%$ of the thyme oil might be because of the evaporation of volatile components of thyme oil during the process of preparation of the nanoemulsion solutions.

Drug loading is the concentration of the loaded drug per unit weight of the nanoparticle, showing the percentage of mass of the nanoparticle that is owed to the encapsulated drug [38]. The DLs of the nanoemulsion was about $2.83 \mathrm{~g} / 100 \mathrm{~g}$ meaning that $2.83 \%$ of the nanoemulsion weight is composed of the thyme oil.

\subsection{Hydrodynamic Emulsion Particle Diameters and Particle Charge Measurements}

Mean particle diameters of the TM-nanoemulsions were measured by the DLS method, and the results are compiled in Table 1 . Solutions with 1 and $2 \% \mathrm{v} / \mathrm{v}$ essential oil had diameters below $100 \mathrm{~nm}$ demonstrating formation of nanoemulsion. However, emulsion prepared with $3 \% \mathrm{v} / \mathrm{v}$ essential oil had diameter of $165 \mathrm{~nm}$, which is in the range of microemulsions. By increasing the concentration of nanoemulsion from 1 to $3 \% \mathrm{v} / \mathrm{v}$, the particle size increased from 50 to $165 \mathrm{~nm}(p>0.05)$. Because of the higher number of particle collisions and coalescence during emulsification, increasing thyme oil concentration led to increased mean droplets sizes. Because of the lower particle size of the $1 \% \mathrm{v} / \mathrm{v}$ nanoemulsion, it was used as the drug model in this study. 
Table 1. Hydrodynamic diameter of emulsions.

\begin{tabular}{cccc}
\hline Sample & $\mathbf{N 1}{ }^{*}$ & $\mathbf{N 2}{ }^{*}$ & N3 \\
\hline Dia. $(\mathrm{nm})$ & $50 \pm 8$ & $68 \pm 10$ & $165 \pm 13$ \\
PDI & $0.188 \pm 0.001$ & $0.202 \pm 0.003$ & $0.26 \pm 0.004$ \\
\hline
\end{tabular}

* N1 = Nanoemulsion $1 \% \mathrm{v} / \mathrm{v}, \mathrm{N} 2$ = Nanoemulsion $2 \% \mathrm{v} / \mathrm{v}, \mathrm{N} 3=$ Nanoemulsion $3 \% \mathrm{v} / \mathrm{v}$.

Polydispersity index (PDI) values are also given in Table 1. PDI shows the uniformity of particle diameter in an emulsion. By increasing the value of polydispersity, the uniformity of nanoemulsion particle size decreases [47]. PDI is defined as the ratio of the standard deviation from the mean particle diameter to the mean particle diameter [47]. PDI is dimensionless, and values smaller than 0.07 are seldom observed except for highly monodisperse systems [48]. PDI values higher than 0.7 are assigned for samples with a very vast size distribution and are not appropriate for DLS analysis [49]. Polydispersity values near 1.0 indicate a polydisperse system [50]. TM-nanoemulsions had low PDI values which indicate their stability and uniformity.

\subsection{Morphology}

Microscopic examination of the TM-PEC films provided information about the homogeneity of the samples. Figure S1 presents the microscopic images of the TM-PEC films. Although both films appeared homogeneous, their comparison showed that TM-PEC $\% 1$ had a less dense structure than the more compact TM-PEC $\% 0.4$ film. Chitosan could decrease the network densities because it may induce relatively entangled porous sizes and perturb the stable three dimensional polymer networks [51].

The morphology of the films was investigated by SEM to observe film surface and cross section structures, homogeneity, and porosity of the composite PEC films. The SEM photos of the surface and cross section of the TM-PEC films incorporated with nanoemulsion are presented in Figure 2. The morphological structures of the PECs-TM were composed of a dense outer surface layer and a porous inner cross-section layer. TM-PEC films showed a relatively flat and smooth surface but irregular cross-sectional morphology. It was found that with increasing content of chitosan, structural irregularity and porosity increased.

(a)

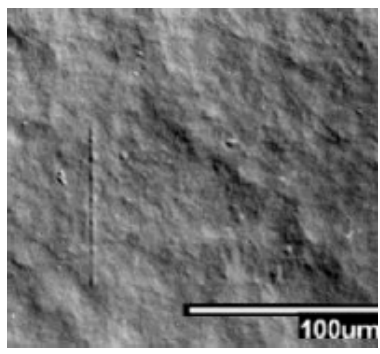

(b)

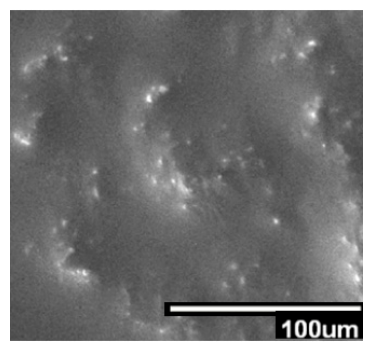

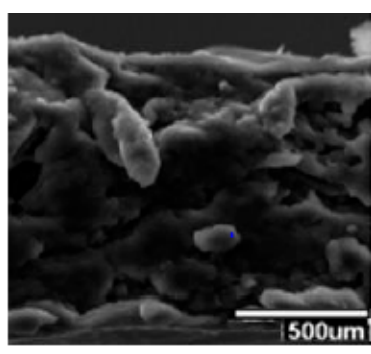

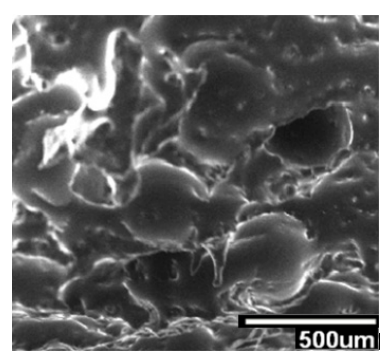

Figure 2. SEM Photos of (a) TM-PEC \%0.4 (b) TM-PEC \%1: Surface (left) and cross section (right). 


\subsection{FTIR Analysis}

The FTIR spectrum of chitosan (Figure 3) displayed vibrational peaks at $3360 \mathrm{~cm}^{-1}(\mathrm{O}-\mathrm{H}$ and $\mathrm{N}-\mathrm{H}$ stretch), $2877 \mathrm{~cm}^{-1}$ (C-H stretch), $1647 \mathrm{~cm}^{-1}$ (amide), $1561 \mathrm{~cm}^{-1}$ (N-H bending of amine), $1152 \mathrm{~cm}^{-1}$ (antisymmetric stretch C-O-C and C-N stretch), and $1032 \mathrm{~cm}^{-1}$ (skeletal vibration of C-O stretch) [52]. The alginate spectrum showed vibrations at $3600-3000 \mathrm{~cm}^{-1}\left(\mathrm{O}-\mathrm{H}\right.$ stretch), $1600 \mathrm{~cm}^{-1}$ (COO-antisymmetric stretch), $1412 \mathrm{~cm}^{-1}$ (COO-symmetric stretch), $3000-2850 \mathrm{~cm}^{-1}$ (C-H stretching), and $1085-1032 \mathrm{~cm}^{-1}$ (C-O-C antisymmetric stretch). The peak at $1637 \mathrm{~cm}^{-1}$ for alginate and chitosan mixture (blank PEC film without TM-nanoemulsion) is assigned to the superposition of the carboxylate group on alginate and the amine/amide groups on chitosan. These results proved that the carboxylate groups $(-\mathrm{COO})$ of alginate react with the protonated chitosan amino groups $\left(-\mathrm{NH}^{+}\right)$by electrostatic attraction to form the polyelectrolyte complex. The interactions between amide bonds on chitosan and the protonated carboxylate groups on alginate could also form intermolecular hydrogen bonds between the polymers [53]. The FTIR band between 2955 and $2863 \mathrm{~cm}^{-1}$ is related to stretching of the thyme oil $\mathrm{CH}_{3}$ group. Peaks at 1350 and $1250 \mathrm{~cm}^{-1}$ are attributed to $\mathrm{OH}$ in-plane bending and $\mathrm{C}-\mathrm{O}$ stretching vibrations from the thyme oil phenol group, respectively $[54,55]$. The band at $800 \mathrm{~cm}^{-1}$ is ascribed to out of plane aromatic $\mathrm{C}-\mathrm{H}$ wagging vibrations [56].

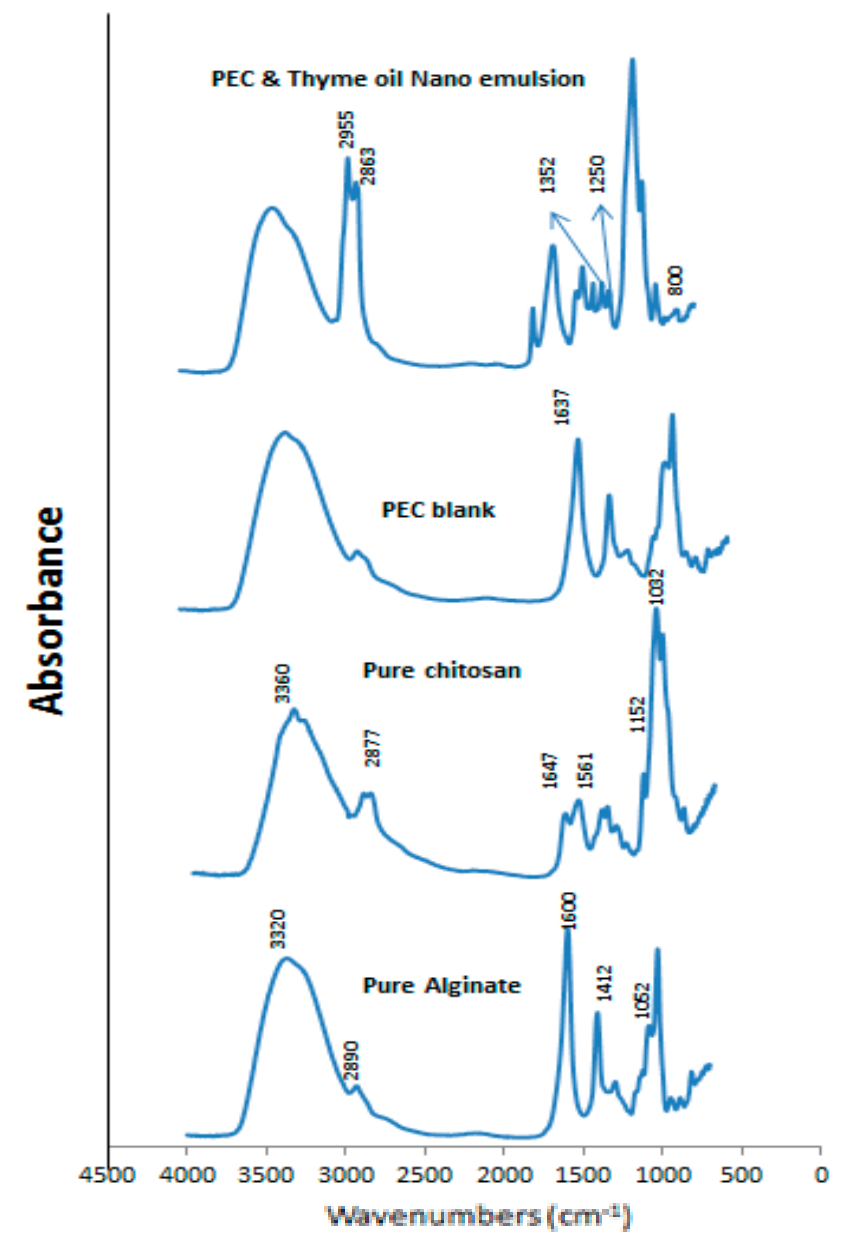

Figure 3. FTIR results.

\subsection{Swelling Ratio}

All of the PEC films showed a fast swelling rate (Figure 4) that can be attributed to their large capacity (macro pores in the film), which let the films absorb large amount of water [57]. TM-PEC $\% 0.4$ film had a final lower swelling ratio in comparison with that of TM-PEC $\% 1$. The reason may be 
because TM-PEC $\% 1$ has less crosslinked functional groups, so there is less resistance against expansion and penetration of water molecules into its structure. While TM-PEC $\% 0.4$ has more functional groups leading to a more confined structure and less swelling ratio. After $5 \mathrm{~h}$, the swelling ratio of both PEC films reached a relatively constant maximum value. Both structures had a gradual weight loss and deswelling. Due to the incomplete reaction, there are some unreacted alginate and chitosan molecules in the solution, which are solved from the membrane into water and can be responsible for some weight loss of the chitosan-alginate PEC membranes after swelling.

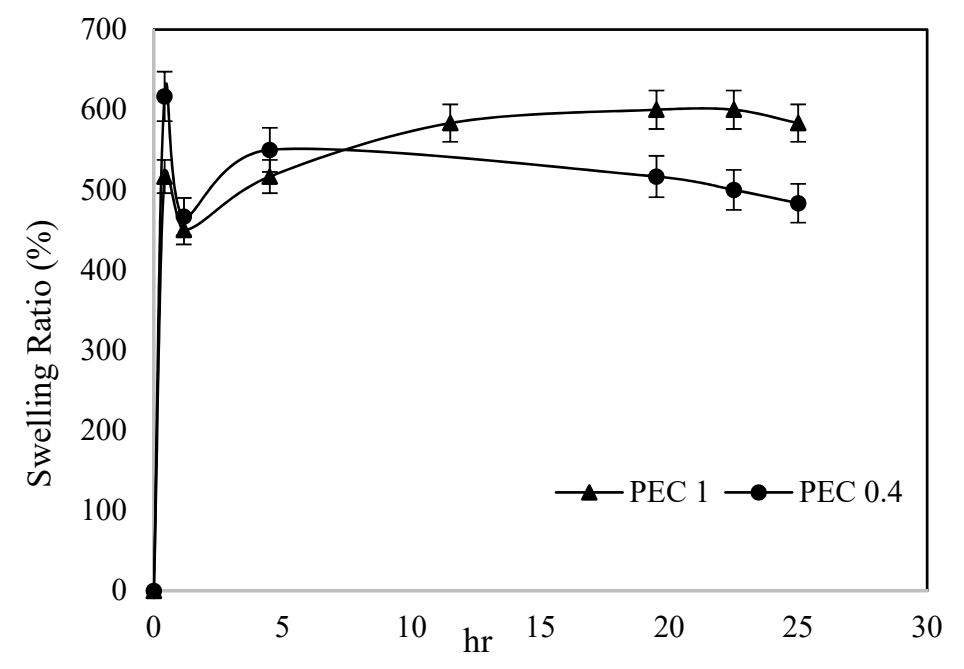

Figure 4. Swelling ratio of PEC films.

\subsection{Water Vapor Transmission Rate (WVTR)}

Controlling the water loss from wound surface in order to prevent excessive dehydration is an essential factor for an ideal wound dressing [58]. Lamke et al. [59] reported that the water vapor loss rates for normal skin, granulating wound, and first-degree burn are $204 \pm 12,5138 \pm 202$, and $279 \pm 26 \mathrm{~g} / \mathrm{m}^{2} /$ day, respectively. A rate of $2000-2500 \mathrm{~g} / \mathrm{m}^{2} /$ day should maintain an appropriate moisture level without wound dehydration [60]. However, some commercial wound dressings, such as Geliperms (Geistlich Ltd., Switzerland) and Vigilons (Bard Ltd., Crawley, UK) have been reported to have a WVTR of $9009 \pm 319$ and $9360 \pm 34 \mathrm{~g} / \mathrm{m}^{2} /$ day, respectively [61], which may dry the wound surface causing the dressing to adhere, requiring a secondary dressing to prevent water vapor loss. The calculated WVTR for the chitosan/alginate PEC films were in the range of $1900-2200 \mathrm{~g} / \mathrm{m}^{2} /$ day and in the ideal range for use as wound dressings (Table 2). WVTR values of TM-PEC $\% 0.4$ and TM-PEC $\% 1(p>0.05)$ were very similar. Incorporating TM-nanoemulsion decreased the WVTR $(p>0.05)$. Regarding the data obtained, the prepared films have the potential capability to keep a sufficient level of moisture to build up exudates on the wound surface.

Table 2. Water vapor transmission rate.

\begin{tabular}{ccccc}
\hline Samples & PEC 0.4 & TM-PEC \%0.4 & PEC 1 & TM-PEC \%1 \\
\hline WVTR $\left(\mathrm{g} / \mathrm{m}^{2} /\right.$ day $)$ & $2189.2 \pm 35$ & $2016.99 \pm 27$ & $1929.7 \pm 68$ & $1922.6 \pm 45$ \\
\hline
\end{tabular}

\section{7. $p H$ Sensitivity}

The $\mathrm{pH}$ sensitivity of the PEC film is shown in Figure 5. When the buffer solution $\mathrm{pH}$ is low, the functional $-\mathrm{NH}_{2}$ groups of chitosan are protonated $\left(-\mathrm{NH}_{3}{ }^{+}\right)$, and most of the carboxyl groups in alginate are in the form of $-\mathrm{COOH}$. Therefore, in a solution with $\mathrm{pH}$ of 4 (Acidic medium), charged chitosan chains repulse each other, leading to the expansion of the films and increased swelling ratios. As the $\mathrm{pH}$ increased, the degree of ionization of chitosan decreased and the carboxylic acid groups 
in alginate became ionized. Electrostatic interactions between $-\mathrm{NH}^{+}$and $-\mathrm{COO}^{-}$became stronger step by step, and more compressed films with lower swelling ratios formed [32]. By increasing the $\mathrm{pH}$ value from 4 to 10 , the swelling ratio decreased $(p>0.05)$. Because of the higher amount of chitosan in TM-PEC $\% 1$ film, its swelling ratio was much higher (about $800 \%$ ) at $\mathrm{pH}=4$. However, by increasing the $\mathrm{pH}$, it became denser and more compact leading to a low swelling value $(37 \%$ for $\mathrm{pH}=10)$. This decrease was less $(p>0.05)$ for the TM-PEC $\% 0.4$ film with a lower chitosan content (from $170 \%$ for $\mathrm{pH}=4$ to $24 \%$ for $\mathrm{pH}=10$ ).

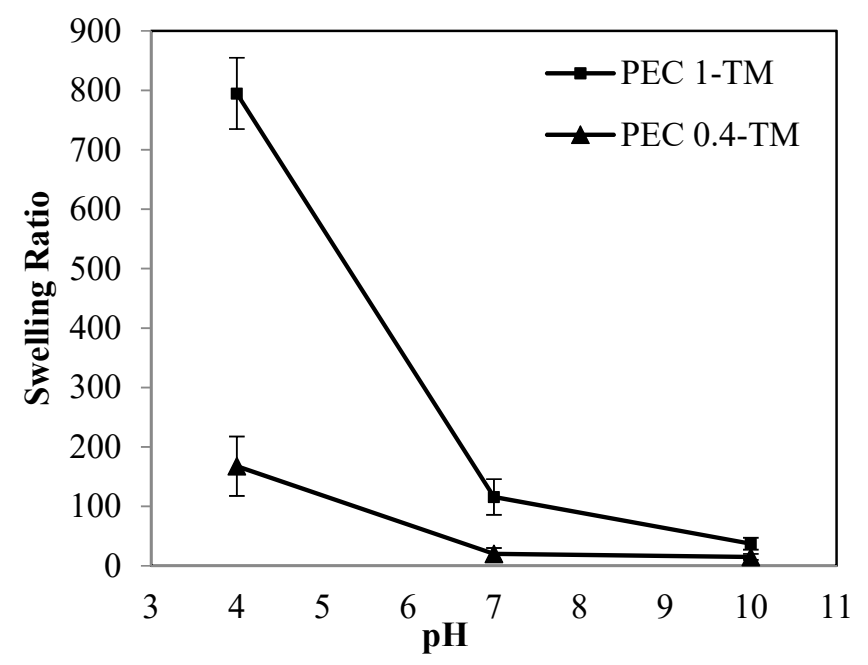

Figure 5. pH Sensitivity of TM-PEC films.

\subsection{Mechanical Tests}

The mechanical properties of the PEC films in the form of their tensile strength, elongation at break, and Young's modulus were calculated from their stress-strain observations and the results are shown in Table 3. Tensile strength evaluates the strength and elongation at break point indicating stretchability of the film before breakage. The maximum stress in TM-PEC \%1 (2.24 Mpa) was higher than that of TM-PEC \%0.4 (0.94 Mpa). This may be caused by increasing the amount of chitosan and alginate and interactions between functional groups leading to a more crosslinked and confined and less elastic structure.

Table 3. Mechanical properties of the PEC films.

\begin{tabular}{cccc}
\hline Sample & Tensile Stress (MPa) & \% Strain & Young's Modulus (kPa) \\
\hline TM-PEC \%0.4 & $0.94 \pm 0.08$ & $9.72 \pm 1.27$ & $106.77 \pm 23.57$ \\
TM-PEC \%1 & $2.24 \pm 0.22$ & $8.52 \pm 1.62$ & $265.87 \pm 32.50$ \\
\hline
\end{tabular}

The modulus of elasticity or Young's modulus describes the stiffness of materials and is one of the most important properties of solid materials. From Hook's law, the modulus of elasticity is defined as the ratio of the stress to the strain [62]. The Young's modulus (stiffness) of the PEC film increased with increasing concentration of chitosan and alginate. Increase in film stiffness can be assigned to the formation of new functional groups which affect polymer interaction and orientation in the film [3].

\subsection{Cytotoxicity Test}

Evaluation of toxicity of the TM-PEC films and TM-nanoemulsion was performed by MTT assay, and the results are presented in Figure 6. After $24 \mathrm{~h}$, extracts of both TM-PEC films and TM-nanoemulsion showed 102-104 and 84\% metabolically active cells in comparison with cells without the medicine $(71 \%-74 \%$, negative controls), respectively. By increasing the contact time to 
$48 \mathrm{~h}$, cell viability of TM-nanoemulsion reached $90 \%$ and remained relatively constant (103\%) for TM-PEC $\% 1$ film. The TM-PEC $\% 0.4$ film had a lower level of cell viability after $48 \mathrm{~h}$. This can be explained by the effect of some thyme oil ingredient, such as thymol and carvacrol, on cell growth and proliferation [63,64]. Carvacrol is a new and natural anticancer drug for human OSCC (oral squamous cell carcinoma). It could suppress human OSCC cancer cells' proliferation by a series of biological pathways including cell cycle regulation, apoptosis, tumorigenesis, adhesion, and invasion [63]. Additionally, the MTT assay and colony formation assays illustrated the function of carvacrol in cell growth and proliferation [63]. Thymol is considered as an oxygenated compound and the role of $\mathrm{O}_{2}$ in stimulating cell proliferation has been described in many literatures $[65,66]$, this may explain the role of thymol in stimulating the growth of fibroblast [67]. It can be hypothesized that the incorporation of thymol into the dressings might have improved the collagenization by modulating fibroblasts growth [64].
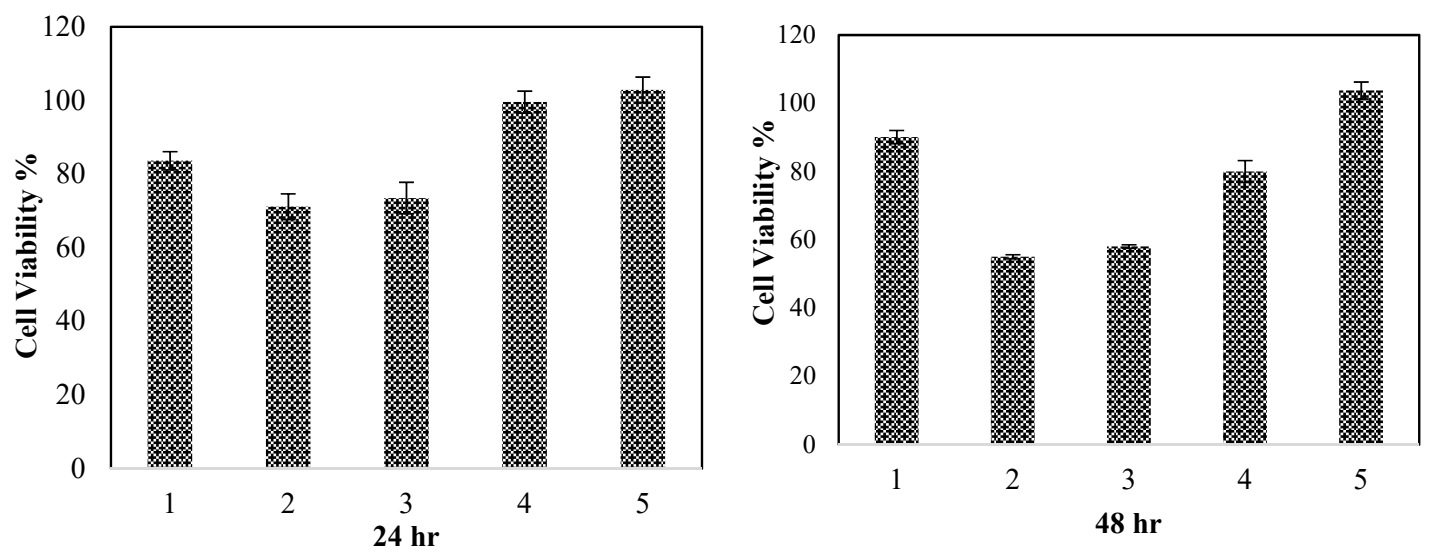

Figure 6. Cell viability of the PEC films: (1) TM-nanoemulsion, (2) PEC 1, (3) PEC 0.4, (4) TM-PEC $\% 0.4,(5)$ TM-PEC \%1.

It can be concluded from the results of MTT assay that the TM-PEC 1\% was not cytotoxic and TM-nanoemulsion and TM-PEC $0.4 \%$ had low-toxicity in the term of fibroblast cells; therefore, the films could be a good candidate for in vivo assay.

\subsection{Antibacterial Test}

The antibacterial test of TM-PEC films and TM-nanoemulsion against E. coli and S.aureus were tested by using the viable cell-counting method. The antibacterial activities of thyme essential oil against E.coli and S.aureus have been investigated previously [65-67]. Figure 7 shows quantitative amounts of survival E. coli for PEC films (with and without drug) and TM-nanoemulsion. The number of bacteria in TM-nanoemulsion decreased in comparison with that without thyme oil. This decrease was significant for TM-nanoemulsion of $2 \mathrm{v} / \mathrm{v} \%$ indicating the dependency of antibacterial activity on concentration of nanoemulsion, which can be related to the hydrophobicity of the thyme oil due to the hydrophobic phenolic constituents such as carvacrol and thymol. The hydrophobic thyme oil diffuses in the lipid layer of the cell membrane, which could lead to deterioration and increase permeability of the membrane [68]. It has been assumed that the phenolic components, such as thymol and carvacrol, suppress the calcium and potassium transport by partitioning in the lipid phase of the membrane and subsequently changing the local environment of calcium channels [69]. Calcium has an established role in the normal homeostasis of mammalian skin and serves as a modulator in keratinocyte proliferation and differentiation [70]. 

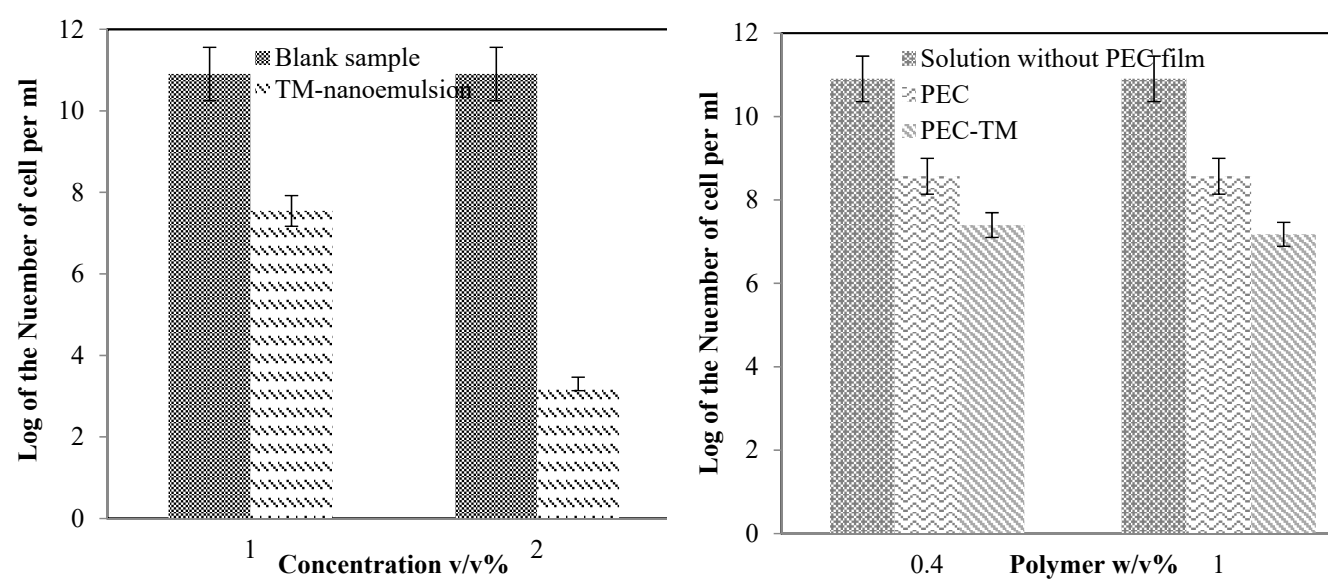

Figure 7. Antibacterial activities of TM-PEC films and TM-nanoemulsions against E.coli.

The number of E.coli in TM-PEC films also decreased in comparison with that of negative control but was comparable with the initial number of bacteria (inoculum) indicating that the TM-PEC films could limit the growth of bacteria $(p<0.05)$. Adding more chitosan did not have an obvious effect, which may be explained by the interaction between positively charged chitosan molecules and negatively charged microbial cell membranes. It has been shown that higher positive charge leads to the stronger antibacterial activity. The formation of polyelectrolyte complexes is mainly because of an electrostatic mechanism, so positive charge density on chitosan decreased. The electrostatic interactions between the polycationic structure and the anionic components of the microorganisms' surfaces is a basic factor in the antibacterial activity of chitosan [42].

The quantitative amounts of survival S.aureus bacteria for PEC films (with and without drug) and TM-nanoemulsion are also shown in Figure 8. Same results were observed. The number of bacteria in TM-nanoemulsion decreased in comparison with that of without thyme oil. This reduction was significant for TM-nanoemulsion of $2 \mathrm{v} / \mathrm{v} \%$ indicating the dependency of antibacterial activity on concentration of nanoemulsion (same as E.coli). The number of S.aureus in TM-PEC films also decreased in comparison with that of negative control but was comparable with the initial number of bacteria (inoculum) showing that the PEC films could limit the growth of bacteria. In all cases, a solution without any PEC film (containing only E.coli or S.aureus bacteria solution) was chosen as the negative control.
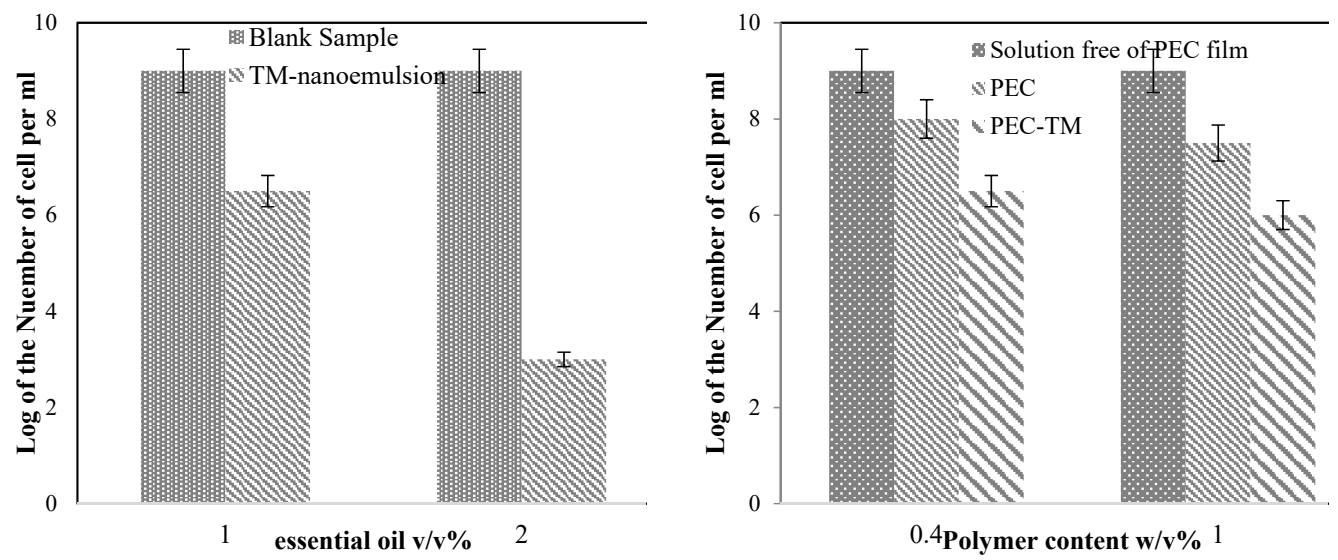

Figure 8. Antibacterial activities of TM-PEC films and TM-nanoemulsions against S.aureus.

It should be mentioned that in the antibacterial tests, although the growth medium is not similar to the wound exudates, it simulates the worst condition where the number of bacteria is much higher than may present at a wound surface. The prepared growth culture provides the best conditions in 
terms of medium composition, $\mathrm{pH}$, and temperature for the growth of test microorganisms, which leads to the maximum growth and activity of the microorganisms. Therefore, it can be concluded that higher activity is expected in real cases as wound surface and exudates do not maintain optimum growth conditions for the microorganisms. On the other hand, the natural defense mechanism during healing process also helps to prevent the growth of bacteria [71].

\subsection{Drug Release}

The main effective components of thyme oil are thymol and carvacrol. The UV spectrum of thymol and carvacrol showed maximum absorption at $274 \mathrm{~nm}$ [72], so the cumulative thyme oil release of PEC films was monitored at this wavelength. Values of thyme oil release for both TM-PEC films are presented in Figure 9. TM-PEC $\% 1$ and $\% .4$ films had initial release of $60 \%$ and $15 \%$ in the first $6-7 \mathrm{~h}$, respectively. The first release phase may be related to the dissolution of drug adsorbed onto the surface of the films. During this time, the drug molecules are desorbed from the film surfaces and diffuse into the dissolution medium [42]. After this initial release, there was a long slow release period where a cumulative release of around $77 \%$ and $20 \%$ in TM-PEC $\% 1$ and $\% 0.4$ films was achieved during the next $100 \mathrm{~h}$. By increasing the amount of chitosan from $0.4 \%$ to $1 \%$, the porosity increased more, and the density of cross linking in the final network decreased, which resulted in an accelerated drug release.

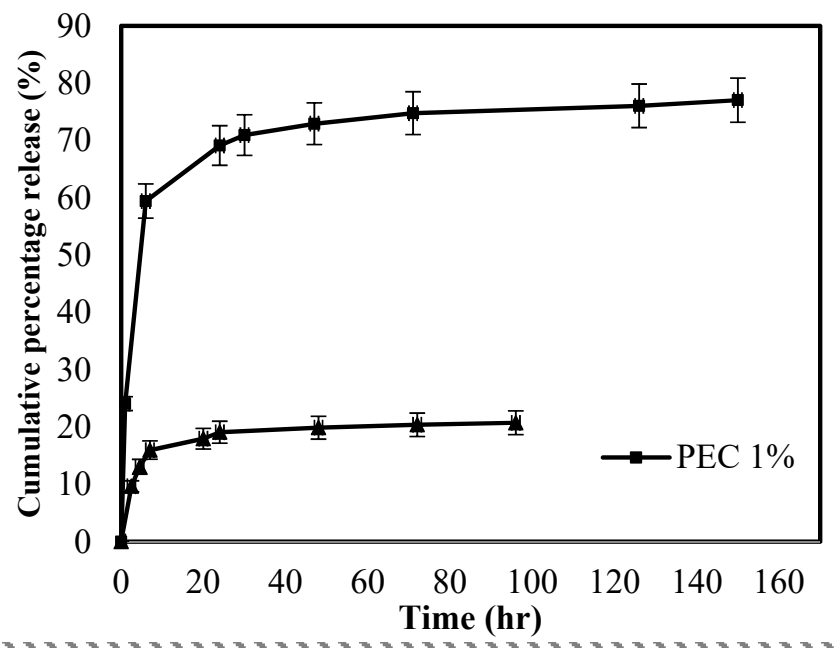

Figure 9. Drug releases of TM-PEC films.

Method validation was performed by calculating the LOD, LOQ, linearity, and accuracy for the loaded nanoemulsion-TM. The calculated LOD and LOQ values were 1.01 and $3.39 \mu \mathrm{g} / \mathrm{L}$, respectively. The calibration curve equation was $y=0.0048 x+0.1031$ with a regression coefficient of $r^{2}=0.9968$. Good linearity was calculated for TM-PEC films demonstrating the accuracy of the obtained calibration curve and drug release calculation.

\subsection{Drug Release Mechanism and Kinetics}

The drug release data were fitted to all mathematical models considered here over two different time ranges ( $0-6$ and after $6 \mathrm{~h}$ ) [73]. The highest value of the regression coefficients was assumed to determine the best mathematical model of drug release kinetics [44]. Table 4 presents the results of $n$ and $\mathrm{k}$ values for both films, which showed excellent linearity $\left(\mathrm{r}^{2}=0.91-1.00\right)$. The values of $\mathrm{n}$ for both PEC films in the first $6 \mathrm{~h}$ were 0.5 indicating that both films follow a Fickian model. After $6 \mathrm{~h}$, however, there was a statistically significant $(p<0.05)$ decrease ( 0.06 and 0.08 for TM-PEC $\% 1$ and TM-PEC $\% 0.4$, respectively), where the mechanism of drug release would be considered as a Pseudo-Fickian diffusion mechanism based on the Korsmeyer-Peppas equation [74]. By increasing the concentration of PEC from 0.4 to $1 \%$, the kinetic constant $\mathrm{k}$ increased showing an increased drug release. 
Table 4. Parameters of release mechanism and regression coefficients of different models fitted to the release of thyme oil.

\begin{tabular}{ccccccccc}
\hline Sample & $\begin{array}{c}\text { Release } \\
\text { Exponent, } \mathbf{n}\end{array}$ & $\begin{array}{c}\text { Kinetic } \\
\text { Constant, } \mathbf{k}\end{array}$ & Peppas & Zero-Order & First-Order & Higuchi & $\begin{array}{c}\text { Hixson-Crowell } \\
\text { Time Range } \\
\text { (hr) }\end{array}$ \\
\hline TM-PEC \%1 & 0.50 & 0.24 & 1.00 & 0.93 & 0.98 & 0.89 & 0.97 & $0-6$ \\
TM-PEC \%1 & 0.06 & 0.59 & 0.97 & 0.87 & 0.90 & 0.87 & 0.89 & $7-150$ \\
TM-PEC \%0.4 & 0.49 & 0.06 & 0.99 & 0.92 & 0.93 & 0.88 & 0.93 & 0.87 \\
TM-PEC \%0.4 & 0.08 & 0.14 & 0.91 & 0.83 & 0.83 & 0.83 & 0.84 & $7-100$ \\
\hline
\end{tabular}

In the first-order model a constant fraction of drug in the body is eliminated per unit of time, while zero-order kinetics describes the process of constant drug release from a drug delivery system, and drug level in the blood remains constant during the delivery [38]. In both time ranges, the released drug data fitted the first-order model indicating that the release rates are directly related to the concentration of drug and do not follow the zero-order release kinetics due to their lower values of regression coefficient in comparison with that of first-order model (Table 4).

Higuchi describes the drug release as a diffusion process based on Fick's law with a square root time dependence and hypothesizes that the swelling of matrix and dissolution are small or negligible [75]. The Hixson-Crowell cube root law describes the release from systems where there is a change in surface area and diameter of particles or tablets [76]. This model assumes that the release rate is limited by the dissolution rate of drug particles and not by drug diffusion [77] During the initial 0-6 $\mathrm{h}$, the release data followed the Hixson-Crowell model closely, with high values of regression coefficients $0.93-0.97$. This supports drug dissolution as the main kinetic barrier to drug release due to changing polyelectrolyte structure. After $6 \mathrm{~h}$, the drug release became stable, and by comparison between the fitted release data, it can be observed that there is little difference between the Higuchi and Hixson-Crowell models (0.83-0.87 in comparison with 0.84-0.89). Actually, after $6 \mathrm{~h}$, drug diffusion through the PEC matrices becomes more effective (Table 4).

\section{Conclusions}

Polyelectrolyte complexes of chitosan and alginate loaded with TM-nanoemulsion as a medicine model were prepared by a casting/solvent evaporation method. FTIR spectra indicated formation of alginate-chitosan PEC films loaded with thyme oil. The homogeneity of the Thyme oil alginate-chitosan PEC films were confirmed by optical and scanning electron microscopy. The $\mathrm{pH}$ sensitivity test indicated that swelling ratio of both PEC films decreased as $\mathrm{pH}$ increased. The final PEC films had good mechanical properties, and the WVTR of the films were in the range of an ideal wound dressing. MTT assay showed lower toxicity of TM-PEC $\% 1$ in comparison with that of TM-PEC \%0.4. TM-PEC films could limit the growth of both gram-negative E.coli and gram-positive S. aureus bacteria. Drug release from the TM-PEC $\% 1$ film was much faster than that of TM-PEC $\% 0.4$ film. It was understood that dissolution was the main factor in the drug release mechanism for all systems especially in the initial hours. Our results suggest that the prepared TM-PEC films may be appropriate for use in the controlled release of drugs or smart wound dressings when loaded with antibacterial essential oils like thyme oil.

Supplementary Materials: The following are available online at http://www.mdpi.com/2076-3417/9/18/3933/s1, Figure S1: Optical Microscopy images of (a) PEC 0.4-TM and (b) PEC 1-TM, Table S1: Interpretation of diffusional release mechanisms.

Author Contributions: Conceptualization, H.H. and S.M.; methodology, H.H.; validation, H.H. and S.M.; formal analysis H.H. and S.M.; investigation, H.H. and S.M.; resources, A.E.T. and S.M.H.; data curation, A.E.T.; writing - original draft preparation, H.H. and S.M.; writing - review and editing, H.H., S.M., A.E.T. and S.M.H.; supervision, A.E.T.; project administration, H.H. and S.M.; funding acquisition, A.E.T. and S.M.H.

Funding: This research received no external funding.

Conflicts of Interest: The authors declare no conflict of interest. 


\section{References}

1. Buriuli, M.; Verma, D. Polyelectrolyte Complexes (PECs) for biomedical applications, Advances in Biomaterials for Biomedical Applications. Adv. Struct. Mater. 2017, 66, 45-93.

2. Meng, X.; Tian, F.; Yang, J.; He, C.N.; Xing, N.; Li, F. Chitosan and alginate polyelectrolyte complex membranes and their properties for wound dressing application. J. Mater. Sci. Mater. Med. 2010, 21, 1751-1759. [CrossRef] [PubMed]

3. Wang, L.; Khor, E.; Wee, A.; Lim, L.Y. Chitosan-Alginate PEC Membrane as a Wound Dressing: Assessment of Incisional Wound Healing. J. Biomed. Mater. Res. 2002, 63, 610-618. [CrossRef] [PubMed]

4. Li, Z.; Ramay, H.R.; Hauch, K.D.; Xiao, D.; Zhang, M. Chitosan-alginate hybrid scaffolds for bone tissue engineering. Biomaterial 2005, 26, 3919-3928. [CrossRef] [PubMed]

5. Florczyk, S.J.; Kim, D.; Wood, D.L.; Zhang, M. Influence of processing parameters on pore structure of 3D porous. J. Biomed. Mater. Sci. 2005, 98, 485-493.

6. Iwasaki, N.; Yamane, S.T.; Majima, T.; Kasahara, Y.; Minami, A.; Harada, K.; Nonaka, S.; Maekawa, N.; Tamura, H.; Tokura, S.; et al. Feasibility of Polysaccharide Hybrid Materials for Scaffolds in Cartilage Tissue Engineering: Evaluation of Chondrocyte Adhesion to Polyion Complex Fibers Prepared from Alginate and Chitosan. Biomacromolecules 2004, 5, 828-833. [CrossRef] [PubMed]

7. Majima, T.; Funakosi, T.; Iwasaki, N.; Yamane, S.T.; Harada, K.; Nonaka, S.; Minami, A.; Nishimura, S.I. Alginate and chitosan polyion complex hybrid fibers for scaffolds in ligament and tendon tissue engineering. J. Orthop. Sci. 2005, 10, 302-307. [CrossRef]

8. Silva, C.M.; Ribeiro, A.J.; Figueiredo, M.; Ferreira, D.; Veiga, F. Microencapsulation of Hemoglobin in Chitosan-coated Alginate Microspheres. AAPS J. 2006, 7, 903-913. [CrossRef]

9. Yong, K.; Mooney, L.D.J. Alginate: Properties and biomedical applications. Prog. Polym. Sci. 2012, 37, 106-126.

10. Sahoo, D.; Nayak, P.L. Chitosan: The Most Valuable Derivative of Chitin. In Biomedical and Environmental Applications; Scrivener Publishing LLC: Beverly, MA, USA, 2011; pp. 129-166.

11. Alexakis, T.; Boadu, D.K.; Quong, D.; Groboillot, A.; O'neill, I.; Poncelet, D.; Neufeld, R.J. Microencapsulation of DNA within alginate microspheres and cross-linked chitosan membranes for in vivo application. Appl. Biochem. Biotechnol. 1995, 50, 9-106. [CrossRef]

12. Koueta, N.; Viala, H.; le Bihan, E. Applications, Uses and By-products from Cephalopods. In Cephalopod Culture; Iglesias, J., Fuentes, L., Villanueva, R., Eds.; Springer: Dordrecht, The Netherlands, 2014; pp. $131-147$.

13. Hamedi, H.; Moradi, S.; Hudson, S.M.; Tonelli, A.E. Chitosan based hydrogels and their applications for drug delivery in wound dressings: A review. Carbohydr. Polym. 2018, 199, 445-460. [CrossRef] [PubMed]

14. Yan, X.L.; Khor, E.; Lim, L.Y. Chitosan-Alginate Films Prepared with Chitosans of Different Molecular Weights. Appl. Biomater. 2001, 358-365. [CrossRef] [PubMed]

15. Lou, Y.; Wang, Q. Recent development of chitosan-based polyelectrolyte complexes with natural polysaccharides for drug delivery. Int. J. Biol. Macromol. 2014, 64, 353-367.

16. Davidson, P. Food Antimicrobials: Back to Nature. In First International Symposium on Natural Preservatives in Food Systems; ISHS Acta Horticulturae: Princeton, NJ, USA, 2005.

17. Gaysinsky, S.; Davidson, P.; McClements, D.; Weiss, J. Formulation and Characterization of Phyto-Phenol-Carrying Antimicrobial Micro emulsions. Food Biophys. 2008, 3, 54-65. [CrossRef]

18. Deans, S.G.; Ritchie, G. Antibacterial properties of plant essential oils. Int. J. Food Microbiol. 1987, 5, 165-180. [CrossRef]

19. Ündeğer, Ü.; Başaran, A.; Degen, G.H.; Başaran, N. Antioxidant activities of major thyme ingredients and lack of (oxidative) DNA damage in V79 Chinese hamster lung fibroblast cells at low levels of carvacrol and thymol. Food Chem. Toxicol. 2009, 47, 2037-2043. [CrossRef]

20. Aydın, S.; Başaran, A.A.; Başaran, N. Modulating Effects of Thyme and Its Major Ingredients on Oxidative DNA Damage in Human Lymphocytes. J. Agric. Food Chem. 2005, 53, 1299-1305. [CrossRef]

21. Hammer, K.A.; Carson, C.F.; Riley, T.V. Antimicrobial activity of essential oils and other plant extracts. J. Appl. Microbiol. 1999, 86, 985-990. [CrossRef]

22. Nardelli, A.; D’Hooghe, E.; Drieghe, J.; Dooms, M.; Goossems, A. Allergic contact dermatitis from fragrance components in specific topical pharmaceutical products in Belgium. Contact Dermat. 2009, 60, 303-313. [CrossRef] 
23. Schilcher, H. Effects and side-effects of essential oils. In Essential Oils and Aromatic Plants; Schilcher, H., Ed.; Springer: Dordrecht, The Netherlands, 1985; pp. 217-231.

24. Moghimi, R.; Ghaderi, L.; Rafati, H.; Aliahmadi, A.; McClements, D.J. Superior antibacterial activity of nanoemulsion of Thymus daenensis essential oil against E. coli. Food Chem. 2016, 194, 410-415. [CrossRef]

25. Rao, J.; McClements, D.J. Food-grade micro emulsions, nanoemulsions and emulsions: Fabrication from sucrose mono palmitate \& lemon oil. Food Hydrocoll. 2011, 25, 1413-1423.

26. Relkin, P.; Jung, J.M.; Ollivon, M. Factors affecting vitamine degradation in oil-in-water nano emulsions. Thermodyn. Anal. Calorim. 2009, 98, 13-18. [CrossRef]

27. Donsì, F.; Annunziata, M.; Sessa, M.; Ferrari, G. Nano encapsulation of essential oils to enhance their antimicrobial activity in foods. LWT-Food Sci. Technol. 2011, 44, 1908-1914.

28. Weiss, J.; Gaysinsky, S.; Davidson, M.; McClements, J. Nanostructured encapsulation systems: Food antimicrobials. In Global Issues in Food Science and Technology; Academic Press: Cambridge, MA, USA, 2009; Chapter 24; pp. 425-479.

29. Loquercio, A. Preparation and Characterization of Chitosan-Alginate Nanoparticles for Trans-Cinnamaldehyde Entrapment. Master's Thesis, Texas A\&M University, College Station, TX, USA, 2014.

30. Al-Kaysi, R.; Muller, A.; Ahn, T.; Lee, S.; Bardeen, C. Effects of Sonication on the Size and Crystallinity of Stable Zwitterionic Organic Nanoparticles Formed by Reprecipitation in Water. Langmuir 2005, 21, 7990-7994. [CrossRef] [PubMed]

31. Hudson Fusion, L.L.C. Sonicator Ultrasonic Liquid Processors; (C) SONICS \& MATERIALS, INC: Newtown, CT, USA, 2014.

32. Gierszewska, M.; Ostrowska-Czubenko, J.; Chrzanowska, E. pH-responsive chitosan/alginate polyelectrolyte complex membranes reinforced by tripolyphosphate. Eur. Polym. J. 2018, 101, 282-290. [CrossRef]

33. Florczyk, S.J.; Kim, D.; Wood, D.L.; Zhang, M. Influence of processing parameters on pore structure of 3D porous chitosan-alginate polyelectrolyte complex scaffolds. Hournal Biomater. Med. Res. Part A 2011, 98, 614-620. [CrossRef] [PubMed]

34. Tao, F.; Hill, L.E.; Peng, Y.; Gomes, C.L. Synthesis and characterization of b-cyclodextrin inclusion complexes of thymol and thyme oil for antimicrobial delivery applications. LWT Food Sci. Technol. 2014, 59, 247-255. [CrossRef]

35. Abarca, R.L.; Rodríguez, F.J.; Guarda, A.; Galotto, M.J.; Bruna, J.E. Characterization of beta-cyclodextrin inclusion complexes containing an essential oil component. Food Chem. 2016, 196, 968-975. [CrossRef]

36. Wang, X.; Luo, Z.; Xiao, Z. Preparation, characterization, and thermal stability of b-cyclodextrin/soybean lecithin inclusion complex. Carbohydr. Polym. 2014, 101, 1027-1032. [CrossRef] [PubMed]

37. Lihong, F.; Huan, Y.; Yang, J.; Yang, M.; Min, P.; Jin, H. Preparation and characterization of chitosan/gelatin/PVA hydrogel for wound dressings. Carbohydr. Polym. 2016, 146, 427-434.

38. Moradi, S.; Barati, A.; Salehi, E.; Tonelli, A.E.; Hamedi, H. Preparation and characterization of chitosan based hydrogels containing cyclodextrin inclusion compounds or nanoemulsions of thyme oil. Polym. Int. 2019. [CrossRef]

39. Ritger, P.L.; Peppas, N.A. A Simple Equation for Description of Solute Release I. Fickian and non-Fickian Release from Non-Sweliable Devices in The Form of Slabs, Spheres, Cylinders or Discs. J. Control. Release 1987, 5, 23-36. [CrossRef]

40. Gómeza, F.M.; Guerrero, J.; Matsuhiro, B.; Pavez, J. In vitro release of metformin hydrochloride from sodium alginate/polyvinyl alcohol hydrogels. Carbohydr. Polym. 2017, 155, 182-191. [CrossRef] [PubMed]

41. Sung, J.H.; Hwang, M.; Kim, J.; Lee, J.H.; Kim, Y.; Kim, J.H.; Chang, S.W.; Jin, S.G.; Kim, J.A.; Lyoo, W.S.; et al. Gel characterisation and in vivo evaluation of minocycline-loaded wound dressing with enhanced wound healing using polyvinyl alcohol and chitosan. Int. J. Pharm. 2010, 392, 232-240. [CrossRef] [PubMed]

42. Sibaja, B.; Culbertson, E.; Marshall, P.; Broughton, R.M.; Solano, A.A.; Esquivel, M.; Parker, J.; Fuente, L.; Auad, M.L. Preparation of alginate-chitosan fibers with potential biomedical applications. Carbohydr. Polym. 2015, 134, 598-608. [CrossRef] [PubMed]

43. Dash, S.; Murthy, P.N.; Nath, L.; Chowdhury, P. Kinetic Modeling on Drug Release from Controlled Drug Delivery Systems. Acta Pol. Pharm. Drug Res. 2010, 67, 217-223.

44. Gouda, R.; Baishya, H.; Qing, Z. Application of Mathematical Models in Drug Release Kinetics of Carbidopa and Levodopa ER Tablets. J. Dev. Drugs 2017, 6, 8. 
45. Elviri, L.; Foresti, R.; Bianchera, A.; Silvestrib, M.; Bettini, R. 3D-printed polylactic acid supports for enhanced ionization efficiency in desorption electrospray mass spectrometry analysis of liquid and gel samples. Talanta 2016, 155, 321-328. [CrossRef] [PubMed]

46. Carletto, J.S.; de Roux, K.C.; Maltez, H.F.; Martendal, E.; Carasek, E. Use of 8-hydroxyquinoline-chitosan chelating resin in an automated on-line preconcentration system for determination of zinc(II) by F AAS. J. Hazard. Mater. 2008, 157, 88-93. [CrossRef]

47. Jaiswal, M.; Dudhe, R.; Sharma, P.K. Nanoemulsion: An advanced mode of drug delivery system. Biotech 2015, 5, 123-127. [CrossRef]

48. Hughes, J.M.; Budd, P.M.; Grieve, A.; Dutta, P.; Tiede, K.; Lewis, J. Highly monodisperse, lanthanide-containing polystyrene nanoparticles as potential standard reference materials for environmental "nano" fate analysis. J. Appl. Polym. Sci. 2015, 132, 42061. [CrossRef]

49. Malvern Co. Dynamic Light Scattering Common Terms Defined. 2011. Available online: https://www. malvernpanalytical.com/en/learn/knowledge-center/whitepapers/WP111214DLSTermsDefined (accessed on 6 October 2016).

50. Otoni, C.G.; Pontes, S.S.F.; Medeiros, E.A.A.; Soares, N.F.F. Edible Films from Methylcellulose and Nanoemulsions of Clove Bud (Syzygium aromaticum) and Oregano (Origanum vulgare) Essential Oils as Shelf Life Extenders for Sliced Bread. J. Agric. Food Chem. 2014, 62, 5214-5219. [CrossRef] [PubMed]

51. Li, X.; Wu, W.; Liu, W. Synthesis and properties of thermo-responsive guar gum/poly(N-isopropylacrylamide) interpenetrating polymer network hydrogels. Carbohydr. Polym. 2008, 71, 394-402. [CrossRef]

52. Le-Tien, C.; Millette, M.; Mateescu, M.-A.; Lacroix, M. Modified alginate and chitosan for lactic acid bacteria immobilization. Biotechnol. Appl. Biochem. 2004, 39, 347-354. [CrossRef] [PubMed]

53. Ho, Y.C.; Mi, F.L.; Sung, H.W.; Kuo, P.L. Heparin-functionalized chitosan-alginate scaffolds for controlled release of growth factor. Int. J. Pharm. 2009, 376, 69-75. [CrossRef] [PubMed]

54. Rukmani, A.; Sundrarajan, M. Inclusion of antibacterial agent thymol on $\beta$-cyclodextrin-grafted organic cotton. J. Ind. Text. 2011, 42, 132-144. [CrossRef]

55. Mohammed, M.J.; Al-Bayati, F.A. Isolation and identification of antibacterial compounds from Thymus kotscyanus and aerial parts of Dianthus caryophyllus flower buds. Phytomedicine 2009, 16, 632-637. [CrossRef]

56. Schulz, H.; Özkan, G.; Baranska, M.; Krüger, H.; Özcan, M. Chracterization of essential oil plants from Turkey by IR and Raman spectroscopy. Vib. Spectrosc. 2005, 39, 249-256. [CrossRef]

57. Yu, S.H.; Mi, F.L.; Wu, Y.B.; Peng, C.K.; Shyu, S.S.; Huang, R.N. Antibacterial Activity of Chitosan-Alginate Sponges Incorporating Silver Sulfadiazine: Effect of Ladder-Loop Transition of Interpolyelectrolyte Complex and Ionic Crosslinking on the Antibiotic Release. J. Appl. Polym. Sci. 2005, 98, 538-549. [CrossRef]

58. Li, H.; Yang, J.; Hu, X.; Liang, J.; Fan, Y.; Zhang, X. Superabsorbent polysaccharide hydrogels based on pullulan derivate as antibacterial release wound dressing. J. Biomed. Mater. Res. Part A 2011, 98, 31-39. [CrossRef]

59. Lamke, L.O.; Nilsson, G.E.; Reithner, H.L. evaporative water loss from burns and the water permeability of grafts and artificial membranes used in the treatment of burns. Burns 1977, 3, 159-165. [CrossRef]

60. Queen, D.; Gaylor, J.D.S.; Evans, J.H.; Courtney, J.M.; Reid, W.H. The preclinical evaluation of the water vapour transmission rate through burn wound dressings. Biomaterials 1987, 8, 367-371. [CrossRef]

61. Wu, P.; Fisher, A.C.; Queen, D.; Gaylor, J.D. In vitro assessment of water vapor transmission of synthetic wound dressings. Biomaterials 1995, 16, 171-175. [CrossRef]

62. Department of Materials Engineering and Chemistry. Modulus of Elasticity. In Building Materials 10-Testing Methods; Czech Technical University: Prague, Czech Republic, Chapter 15.

63. Dai, W.; Sun, C.; Huang, S.; Zhou, Q. Carvacrol suppresses proliferation and invasion in human oral squamous cell carcinoma. Onco Target Ther. 2016, 9, 2297-2304. [CrossRef] [PubMed]

64. Riella, K.R.; Marinho, R.R.; Santos, J.S.; Pereira-Filho, R.N.; Cardoso, J.C.; Albuquerque-Junior, R.L.C.; Thomazzi, S.M. Anti-inflammatory and cicatrizing activities of thymol, a monoterpene of the essential oil from Lippia gracilis, in rodents. J. Ethnopharmacol. 2012, 143, 656-663. [CrossRef] [PubMed]

65. Farag, R.S.; Dawz, Z.Y.; Hewedi, F.M.; El-Baroty, G.S.A. Antimicrobial Activity of Some Egyptian Spice Essential Oils. J. Food Prot. 1989, 52, 665-667. [CrossRef] [PubMed]

66. Gutierrez, J.; Barry-Ryan, C.; Bourke, P. The antimicrobial efficacy of plant essential oil combinations and interactions with food ingredients. Int. J. Food Microbiol. 2008, 124, 91-97. [CrossRef] [PubMed] 
67. Schelz, Z.; Molnar, J.; Hohmann, J. Antimicrobial and antiplasmid activities of essential oils. Fitoterapia 2006, 77, 279-285. [CrossRef]

68. Lambert, R.J.W.; Skandamis, P.N.; Coote, P.J.; Nychas, G.J.E. A study of the minimum inhibitory concentration and mode of action of oregano essential oil, thymol and carvacrol. J. Appl. Microbiol. 2001, 91, 453-462. [CrossRef]

69. Braga, P.C.; Sasso, M.D.; Culici, M.; Bianchi, T.; Bordoni, L.; Marabini, L. Anti-inflammatory activity of thymol: inhibitory effect on the release of human neutrophil elastase. Pharmacology 2006, 77, 130-136. [CrossRef]

70. Lansdown, A.B. Calcium: A potential central regulator in wound healing in the skin. Wound Repair Regen. 2002, 10, 271-285. [CrossRef] [PubMed]

71. Altiok, D.; Altiok, E.; Tihminlioglu, F. Physical, antibacterial and antioxidant properties of chitosan films incorporated with thyme oil for potential wound healing applications. J. Mater. Sci. Mater. Med. 2010, 21, 2227-2236. [CrossRef] [PubMed]

72. Hajimehdipoor, H.; Shekarchi, M.; Khanavi, M.; Adib, N.; Amri, M. A validated high performance liquid chromatography method for the analysis of thymol and carvacrol in Thymus vulgaris L. volatile oil. Pharmacogn. Mag. 2010, 6, 154-158. [CrossRef] [PubMed]

73. Li, P.; Dai, Y.; Zhang, J.; Wang, A.; Wei, Q. Chitosan-Alginate Nanoparticles as a Novel Drug Delivery System for Nifedipine. Int. J. Biomed. Sci. 2008, 4, 221-228. [PubMed]

74. Sperling, L.H. Concentrated Solutions, Phase Separation Behavior, and Diffusion. In Introduction to Physical Polymer Science, 4th ed.; Wiley Interscience: Hoboken, NJ, USA, 2006; pp. 145-196.

75. Ramteke, K.H.; Dighe, P.A.; Kharat, A.R.; Patil, S.V. Mathematical Models of Drug Dissolution: A Review. Sch. Acad. J. Pharm. 2014, 3, 388-396.

76. Singhvi, G.; Singh, M. Review: In-Vitro Drug Release Characterization Models. Int. J. Pharm. Stud. Res. 2011, 2, 77-84.

77. Chime, S.A.; Onunkwo, G.C.; Onyishi, I.I. Kinetics and Mechanisms of Drug Release from Swellable and Non Swellable Matrices: A Review. Res. J. Pharm. Biol. Chem. Sci. 2013, 4, 97-103.

(C) 2019 by the authors. Licensee MDPI, Basel, Switzerland. This article is an open access article distributed under the terms and conditions of the Creative Commons Attribution (CC BY) license (http://creativecommons.org/licenses/by/4.0/). 